\title{
Floraciones tóxicas de cianobacterias en una laguna pampeana: Una aproximación a su ecología desde los rasgos morfo- fisiológicos
}

\author{
Fiorella T. Cocciolo'; Lilen Yema'; M. Laura Sánchez; Carolina González ${ }^{1 / 2}$ \\ \& INÉS O’FARRELL ${ }^{1, \bigotimes}$
}

${ }^{1}$ Departamento de Ecología, Genética y Evolución, Instituto IEGEBA (CONICET-UBA), Facultad de Ciencias Exactas y Naturales, Universidad de Buenos Aires, Argentina. ${ }^{2}$ Centro de investigaciones, Agua y Saneamientos Argentinos, CABA, Argentina.

\begin{abstract}
RESUMEN. Se realizó la caracterización ecológica del ensamble de cianobacterias formadoras de floraciones de la laguna Salada de Monasterio (SM), provincia de Buenos Aires. Se detectó que la abundancia, la biomasa y la morfología de las especies estuvieron afectadas por las condiciones ambientales de la laguna durante dos períodos cálidos con diferentes niveles hídricos que incidieron en la turbidez y la concentración de fósforo. SM estuvo seriamente afectada por floraciones de cianobacterias tóxicas dominadas por Raphidiopsis mediterranea, acompañada por Planktothrix agardhii, Anabaenopsis cf. circularis, A. cunningtonii y Cuspidothrix issatschenkoi en el primer período, y por $C$. issatschenkoi en el segundo. La abundancia y el biovolumen total de ambos períodos se correlacionaron positivamente y se registró una menor densidad de cianobacterias en el segundo período, con mayor nivel hídrico. En ambos períodos se superó tanto el nivel de alerta 2 para agua de bebida como el nivel guía 2 para aguas de recreación (Organización Mundial de la Salud, OMS) para la abundancia de células de cianobacterias. Entre las especies se detectaron diferencias morfológicas asociadas a respuestas a la disponibilidad de la luz en la columna de agua. En $R$. mediterranea se evidenció una asociación directa entre la longitud y el ancho del filamento que favorece el desarrollo, incluso en escenarios con elevada turbidez y limitación de luz, donde las demás especies no fueron detectadas. El nitrógeno orgánico disuelto (NOD) sería la fuente principal de nitrógeno debido a su elevada concentración (media: $3.76 \mathrm{mg} / \mathrm{L}$ ). La frecuencia de acinetas en Anabaenopsis y C. issatschenkoi fue baja, lo que indica un escenario favorable para su desarrollo. La concentración de microcistina (-LR e -YR) en el primer período superó $1 \mu \mathrm{g} / \mathrm{L}$ (nivel guía OMS), siendo $P$. agardhii y Anabaenopsis las potenciales productoras de esta toxina; no se detectó saxitoxina.
\end{abstract}

[Palabras clave: Cyanobacteria, eutrofización, cianotoxinas, Salada de Monasterio]

Aвstract. Toxic cyanobacterial blooms in a Pampean shallow lake: An approach to their ecology from morpho-physiological traits. This study presents the ecological characterization of the assemblage of bloom forming cyanobacteria from laguna Salada de Monasterio (SM), Buenos Aires. The relationships between abundance, biomass and morphology of the species with the environmental conditions in the shallow-lake along two warm periods are assessed. SM was seriously impaired by toxic cyanobacterial blooms dominated by Raphidiopsis mediterranea, which in the first stage was accompanied by Planktothrix agardhii, Anabaenopsis cf. circularis, A. cunningtonii and Cuspidothrix issatschenkoi, and by C. issatschenkoi in the second period. Total abundance and biovolume of both periods were positively correlated, and a lower density of cyanobacteria was registered in the second period, with a higher water level. The alert level 2 for drinking water and the guide level 2 for recreational waters (World Health Organization, WHO), in terms of the abundance of cyanobacteria cells, were exceeded at both warm periods. The morphological differences observed among species were associated with responses to light availability in the water column. $R$. mediterranea presented a direct association between filament length and width that favoured its development, even in scenarios with high turbidity and light limitation, where the other species were not found. Dissolved organic nitrogen (NOD) is considered the preferred nitrogen source due to its high concentration (average: $3.76 \mathrm{mg} / \mathrm{L}$ ). A low frequency of akinetes was found for Anabaenopsis and C. issatschenkoi, indicating a favorable scenario for their development. Microcystin (-LR and -YR) was registered in the first period with concentrations exceeding $1 \mu \mathrm{g} / \mathrm{L}$ (WHO guidance level), with $P$. agardhii and Anabaenopsis being the potential toxin producers; saxitoxin was not detected.

[Keywords: Cyanobacteria, eutrophication, cyanotoxins, Salada de Monasterio]

Editor asociado: Fernando Unrein

\footnotetext{
ines@ege.fcen.uba.ar
} 


\section{INTRODUCCIÓN}

Las cianobacterias son bacterias fotosintéticas que habitan diversos ambientes acuáticos y presentan una variedad de características fisio-morfológicas que les otorgan ventajas adaptativas frente al fitoplancton eucariota (Carey et al. 2012). Dichas ventajas son la captación de luz a bajas intensidades y en un rango amplio de longitudes de onda, la regulación de la flotabilidad, la capacidad de fijar nitrógeno atmosférico $\left(\mathrm{N}_{2}\right)$, el desarrollo de estructuras de resistencia y la producción de toxinas (Chorus and Bartram 1999; Carey et al. 2012; Huisman et al. 2018). El orden Nostocales comprende especies filamentosas capaces de formar heterocitos para la fijación de $\mathrm{N}_{2} \mathrm{y}$ acinetas que permiten la supervivencia de la población bajo condiciones de estrés (Kaplan and Levy 2010). En situaciones de limitación de nitrógeno, las especies fijadoras de $\mathrm{N}_{2}$ poseen una ventaja competitiva sobre las no fijadoras y sobre el resto de los fitopláncteres (Huisman et al. 2018). La diferenciación de heterocitos en escenarios con limitación de nitrógeno inorgánico disuelto (NID) fue registrada reiteradamente (Schindler 1977; Kahru et al. 2000; Ferber et al. 2004; Vrede et al. 2009; Unrein et al. 2010; Wood et al. 2010; Figueredo et al. 2014), aunque el rol del nitrógeno orgánico disuelto (NOD) en este proceso no está bien documentado. El crecimiento exitoso de Nostocales fue descripto para escenarios en los que el NOD era la fuente principal de nitrógeno: Aphanizomenon ovalisporum en el lago Kinneret (Berman 2001) y Anabaena flosaquae en cultivos del lago Dianchi-China (Qian et al. 2017). Además, Berg et al. (2001) indican que el uso del NOD es importante cuando el NID es limitante.

Las cianobacterias producen una variedad amplia de metabolitos secundarios, incluyendo toxinas (Chorus and Bartram 1999). Las microcistinas (Mcy) son hepatotóxicas y comprenden el grupo estructuralmente más diverso de cianotoxinas (Neilan et al. 2013; Carmichael 2001). Esas cianotoxinas incluyen: Mcy -LR (leucina-arginina), -RR (argininaarginina) e-YR (tirosina-arginina) (NishiwakiMatsuchima et al. 1991). Su presencia en el agua potable y en los sistemas acuáticos puede representar una amenaza para los humanos y, por lo tanto, la Organización Mundial de la Salud (OMS) recomienda un límite de 1 $\mu \mathrm{g} / \mathrm{L}$ de Mcy en el agua de bebida (Chorus and Bartram 1999). Las saxitoxinas, otro grupo de cianotoxinas, son neurotóxicas y han sido menos estudiadas; a pesar de la ausencia de valores guía oficiales de la OMS, algunos países como Brasil recomiendan un límite de $3 \mu \mathrm{g} / \mathrm{L}$ para el agua de bebida (Chorus 2012).

Cuando las condiciones son propicias para el desarrollo de las cianobacterias se puede generar un crecimiento masivo denominado floración. Los factores ambientales claves que solos o combinados promueven la formación de estos eventos son las altas temperaturas, la buena disponibilidad de luz y nutrientes (Merel et al. 2013) y el tiempo de residencia elevado (Zhao et al. 2019). Por lo general, las floraciones de cianobacterias ocurren en sistemas acuáticos eutróficos (Chorus and Bartram 1999), aunque el escenario actual de cambio climático ha acelerado la intensidad de estos eventos (Huisman et al. 2018). Las floraciones representan un riesgo importante porque afectan negativamente a la biota del cuerpo de agua impactado, a las actividades recreativas y económicas, y comprometen el acceso al agua potable para el consumo.

Las lagunas y los estanques son los cuerpos de agua más abundantes en el paisaje global y son un hábitat frecuente de las cianobacterias (Downing et al. 2006). Diovisalvi et al. (2015) observaron que las lagunas de la Región Pampeana están más eutrofizadas que las del resto del globo, presentando mayor concentración de nutrientes y de clorofila $a$, y menor transparencia. La eutrofización progresiva de las lagunas se asocia a actividades humanas como la agricultura, la ganadería y la urbanización (Quirós et al. 2006). En un meta-análisis ecológico de los cuerpos de agua de la Argentina se encontró que la ecorregión pampeana es uno de los territorios más afectados por floraciones de cianobacterias (O'Farrell et al. 2019), confirmando la descripción de Aguilera et al. (2017). En el marco del proyecto PAMPA ${ }^{2}$ (CONICET), la laguna Salada de Monasterio mostró gran desarrollo estival de floraciones de cianobacterias asociado a la creciente eutrofización y variabilidad del nivel hídrico (Izaguirre et al. 2015).

Los objetivos del presente estudio son: 1) realizar una caracterización ecológica de las poblaciones planctónicas de cianobacterias potencialmente tóxicas formadoras de floraciones de la laguna Salada de Monasterio (Buenos Aires) en dos períodos cálidos consecutivos, evaluando si las floraciones de cianobacterias se intensifican (mayor 
densidad) ante un aumento de la temperatura (hipótesis 1a) y ante una disminución del nivel hídrico (hipótesis $1 \mathrm{~b}$ ); 2) analizar la relación entre la morfología de las distintas especies de cianobacterias y las condiciones ambientales de la laguna, evaluando si existe una relación directa entre la turbidez de la laguna y la morfología del organismo (expresada como la relación longitud/ ancho del filamento; hipótesis 2a), y si la diferenciación de heterocitos se ve afectada por las concentraciones de nitrógeno orgánico disuelto (hipótesis 2b), y 3) caracterizar la toxicidad potencial de las floraciones en base a la presencia de microcistinas y saxitoxinas.

\section{Materiales y Métodos}

\section{Área de estudio}

Este estudio se llevó a cabo en la laguna Salada de Monasterio (SM), perteneciente a la cuenca del Río Salado (3546'46.46" S - 5751'39' O), Región Pampeana, Argentina (Figura 1). SM forma parte de la Red de Monitoreo y Prospección de Ambientes Acuáticos (PAMPA ${ }^{2}$ ) (Izaguirre et al. 2015). Como gran parte de las lagunas de la cuenca del río Salado, SM tiene una alta concentración de nutrientes, es polimíctica y su composición iónica está dominada por el sistema sodio-bicarbonato (Fernández Cirelli and Miretzky 2002; Allende et al. 2009). Posee una profundidad media de $1.30 \mathrm{~m}$ y un área superficial de $6 \mathrm{~km}^{2}$ (Izaguirre et al. 2015).

\section{Metodología}

Se analizaron las muestras recolectadas en la zona pelágica de la laguna de noviembre a mayo de 2013-2014 (etapa I) y 2014-2015 (etapa II), abarcando dos períodos cálidos consecutivos que se extendieron hasta el otoño, ya que las floraciones pueden desarrollarse hasta el inicio de esta estación (Izaguirre et al. 2015). Las muestras biológicas de diciembre de 2014 y febrero de 2015 se malograron.

Las variables físicas y químicas fueron registradas mensualmente en la capa subsuperficial de la laguna, junto con la toma de muestras de agua para su análisis en el laboratorio. La temperatura del agua, $\mathrm{pH}$, conductividad y oxígeno disuelto se midieron in situ con instrumentos electrónicos portátiles (HANNA $^{\circledR}$ y HORIBA $^{\circledR}$ ), la transparencia del agua se estimó con el disco de Secchi y la turbidez con un turbidímetro 2100P HACH ${ }^{\circledR}$. Para la determinación de clorofila $a(\mathrm{Chl}-a)$ se filtraron las muestras usando filtros de fibra de vidrio (Whatman GF/F). Las concentraciones de Chl- $a$ se estimaron por espectrofotometría utilizando etanol caliente como disolvente, siguiendo la metodología descrita en Nusch (1980), y se calcularon con ecuaciones de Lorenzen (1967). El nitrógeno orgánico total (NOT, medido a partir de muestras de agua sin filtrar) y el nitrógeno orgánico disuelto (NOD, a partir de muestras filtradas con filtros GF/F) se determinaron mediante el método Kjeldahl (APHA 2005). El fósforo total (FT, de muestras de agua sin filtrar) y el

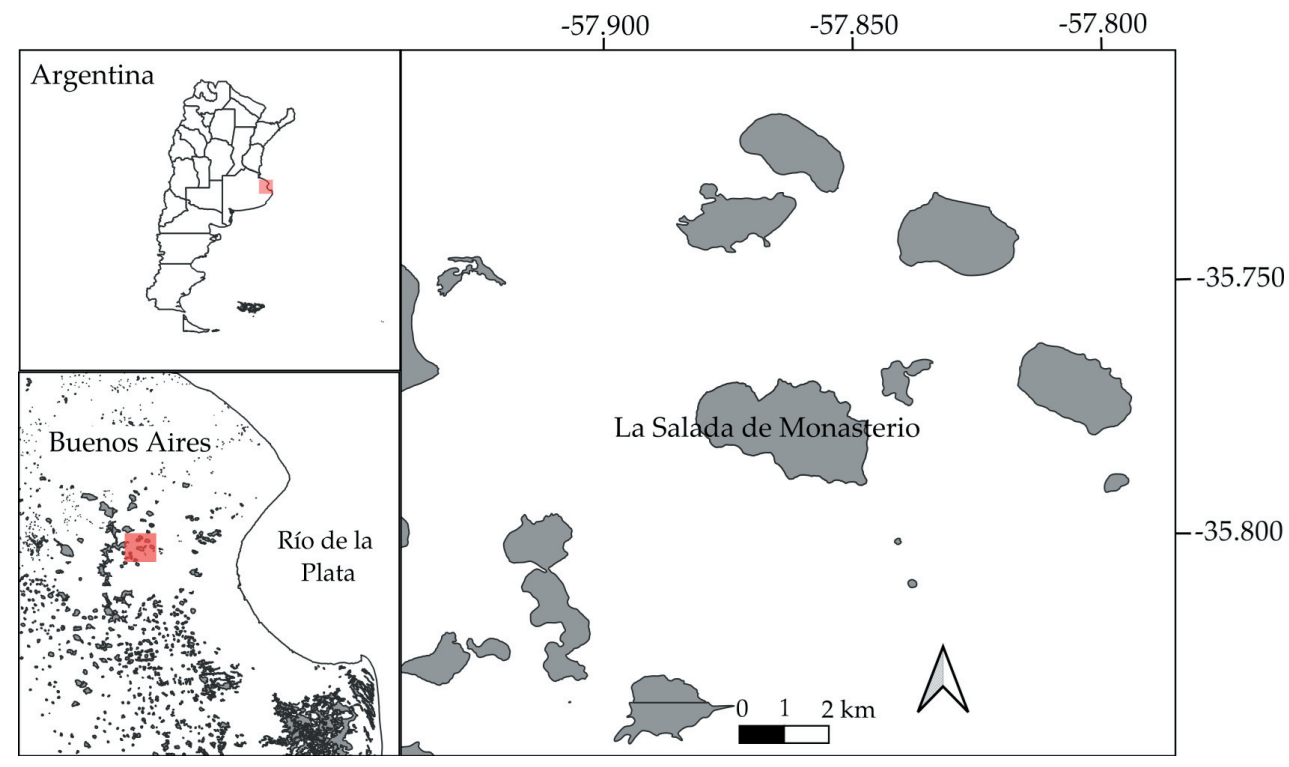

Figura 1. Mapa del área de estudio, laguna Salada de Monasterio (Buenos Aires).

Figure 1. Map of the study area, laguna Salada de Monasterio (Buenos Aires). 
fósforo disuelto (Fdis, de agua filtrada GF/F) se convirtieron en fósforo reactivo soluble después de una digestión ácida con persulfato de potasio, y se determinó por el método del molibdato ascórbico (APHA 2005). Los sólidos suspendidos totales (peso seco total: PST) se estimaron después de la filtración con filtros GF/F previamente secados ponderados, secando en estufa a $105^{\circ} \mathrm{C}$ el residuo no filtrable hasta un peso constante (APHA 2005). El peso seco libre de cenizas, determinado según Vega et al. (2007), fue considerado como peso seco orgánico (PSO) y se lo usó como indicador de la turbidez orgánica. El peso seco inorgánico (PSI) se obtuvo por la diferencia entre el PST y el PSO, y fue utilizado como indicador de la turbidez inorgánica.

El análisis cuantitativo de las especies de cianobacterias se realizó sobre muestras fijadas al 1\% con solución acidificada de Iodo de Lugol; los recuentos fueron realizados a 400X con un microscopio invertido (Olympus CKX41) según Utermöhl (1958). La identificación de las especies de cianobacterias se realizó considerando la presencia, forma y tamaño de atributos morfológicos siguiendo a Komárek and Anagnostidis (2005) y Komárek (2013).

Para el análisis morfológico de las especies de cianobacterias se usó un microscopio óptico (Olympus CX31) que cuenta con una cámara digital y el paquete Lumenera Infinity 2 Analyze $^{\circledast}$. Se tomaron para cada mes y para cada especie los datos morfológicos de 10 a 20 individuos. Para todas las especies encontradas se midió el largo y el ancho del filamento de una célula vegetativa de la zona media del filamento, y se calculó el índice 'longitud/ancho del filamento' como indicador del desempeño del organismo para captar luz (i.e., valores mayores denotan mayor aptitud). Para el orden Nostocales, se contó el número de heterocitos y de acinetas por célula vegetativa cuando estuvieron presentes. Se calculó la densidad y el biovolumen (Hillebrand et al. 1999) como estimadores de la abundancia y biomasa de cianobacterias respectivamente.

El análisis de toxinas se realizó por cromatografía UPLC-MS. Para ello, las muestras se llevaron a temperatura ambiente, se filtraron a través de membranas de Nylon de poro $0.22 \mu \mathrm{m}$ y se colocaron en viales de vidrio de $2 \mathrm{~mL}$. Para la determinación y cuantificación de microcistinas se trabajó con estándares de Mcy-LR, -RR y -YR Sigma-
Aldrich $\AA$, con los cuales se prepararon curvas de calibración elaboradas mediante diluciones seriadas de $10 \mu \mathrm{g} / \mathrm{L}$ a $0.025 \mu \mathrm{g} / \mathrm{L}$. El equipo cromatográfico utilizado fue un UPLC Thermo Scientific Ultimate 3000 acoplado a MS, TSQ Quantum Access Max con ionizador por electrospray en modo positivo (HESI+). Las condiciones de trabajo fueron: Columna C18 $150 \times 2.1 \mathrm{~mm} \times 3 \mu \mathrm{m}$; fase móvil componente A: agua-ácido fórmico al $0.1 \%$; componente B: acetonitrilo-ácido fórmico al $0.1 \%$; temperatura de la columna: $40^{\circ} \mathrm{C}$; volumen de inyección de muestra: $50 \mu \mathrm{L}$; tasa de flujo: $0.15 \mathrm{~mL} / \mathrm{min}$. En cuanto a la determinación y cuantificación de saxitoxinas, se utilizó el estándar de saxitoxina Abraxis ${ }^{\circledR}$, con el que se elaboró una curva de calibración con diluciones seriadas de $10 \mu \mathrm{g} / \mathrm{L}$ a $0.05 \mu \mathrm{g} / \mathrm{L}$. El equipo cromatográfico utilizado fue un UPLC Thermo Scientific Ultimate 3000 RS acoplado a TSQ Quantis. Se trabajó en modo de ionización (HESI+), Columna C18 de $50 \times 2.1 \mathrm{~mm} \times 3 \mu \mathrm{m}$. La fase móvil fue: componente A: $50 \%$ ácido fórmico-agua; componente B: $50 \%$ acetonitrilo-metanol 1/1; volumen de inyección de muestra: $50 \mu \mathrm{L}$; tasa de flujo: $0.5 \mathrm{~mL} / \mathrm{min}$.

\section{Análisis estadístico}

Se realizó una estadística descriptiva de las variables ambientales y morfológicas de las especies. Se compararon las variables ambientales entre ambas etapas de estudio usando la prueba U de Mann-Whitney. Se realizaron análisis multivariados para explorar la variación de los ensambles de cianobacterias en función de las condiciones ambientales de ambas etapas (hipótesis 1): ordenamiento de las variables ambientales durante los meses de estudio (análisis de componentes principales, ACP) y ordenamiento restringido de la abundancia de las especies de cianobacterias (análisis de redundancia, ADR), respectivamente. En el ACP se incluyeron todas las variables ambientales, excepto la conductividad por ser altamente redundante con la profundidad. Para el ADR se analizó la colinealidad de las variables (factor de inflación de la varianza, VIF>10), eliminando del modelo Secchi, PST, PSI, PSO, y conductividad. Por otro lado, se realizaron correlaciones no paramétricas de Spearman entre las variables ambientales, biológicas y morfológicas (hipótesis 2). Para evaluar la existencia de diferencias en el índice longitud/ ancho del filamento de las cinco especies planctónicas formadoras de floraciones de la laguna (hipótesis 2a) se aplicó la prueba de 
Kruskal-Wallis (K-W). Todos los análisis se realizaron con R software 3.6.3 ( $\mathrm{R}$ Core Team 2020) utilizando RStudio. Los análisis uni- y bivariados se realizaron con el paquete stats (R Core Team 2012) y los multivariados con el paquete vegan (Oksanen et al. 2019).

\section{Resultados}

Variables físicas y químicas de la laguna Salada de Monasterio

La caracterización limnológica de la laguna evidenció diferencias de algunas variables
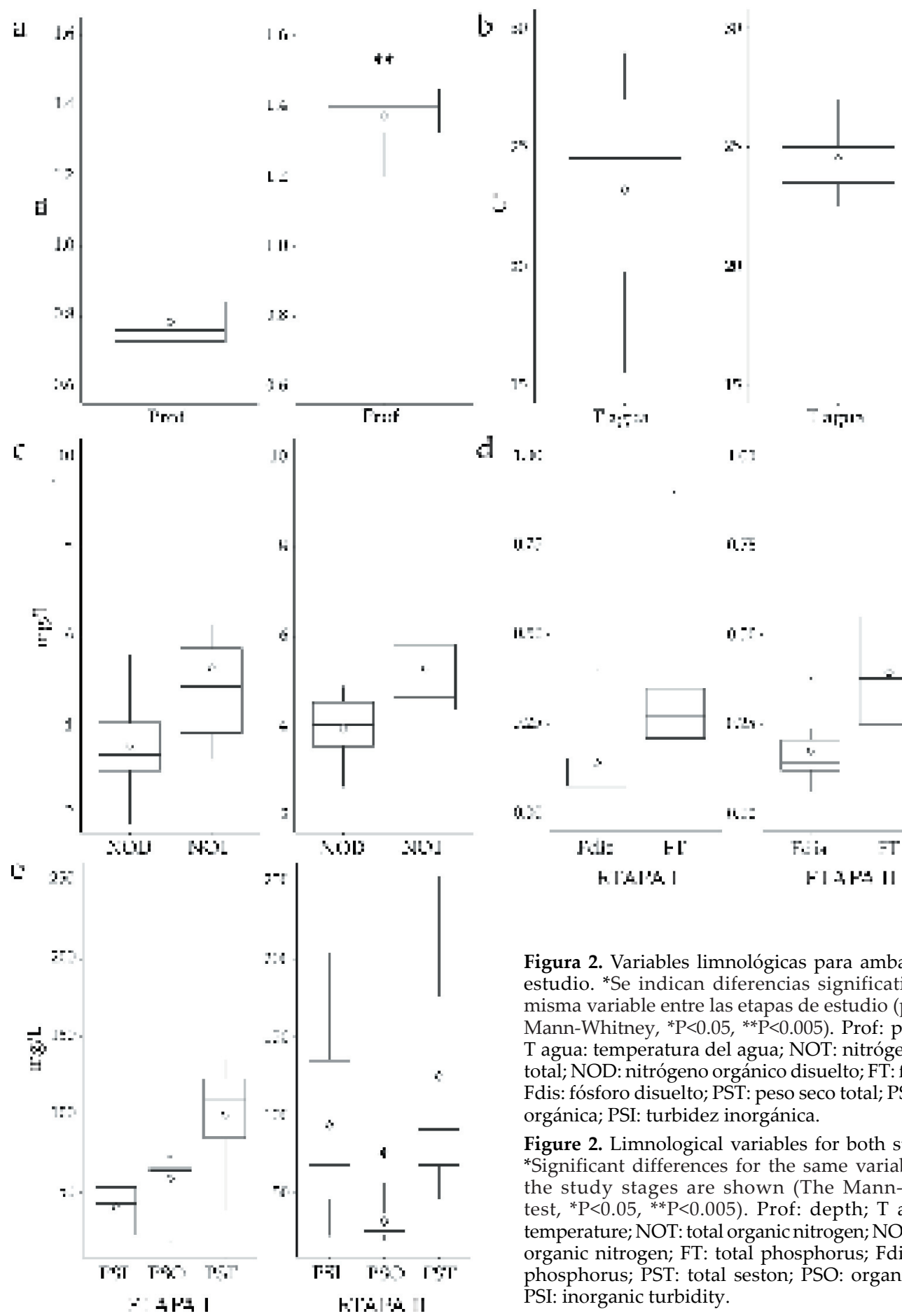

1. $n$ :

$1=$

1):

1.:.

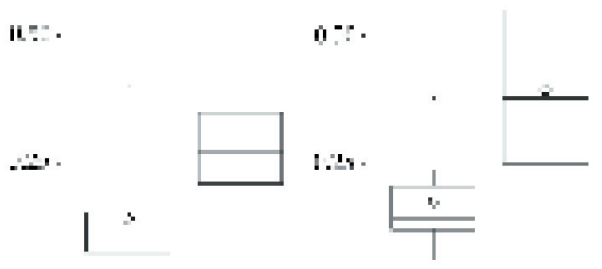

0.

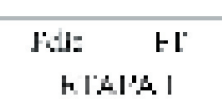

in: =

$$
\begin{aligned}
& \text { F. is } \quad \mathrm{T}
\end{aligned}
$$

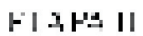

Figura 2. Variables limnológicas para ambas etapas de estudio. ${ }^{*}$ Se indican diferencias significativas para la misma variable entre las etapas de estudio (prueba U de Mann-Whitney, $\left.{ }^{*} \mathrm{P}<0.05,{ }^{* *} \mathrm{P}<0.005\right)$. Prof: profundidad; T agua: temperatura del agua; NOT: nitrógeno orgánico total; NOD: nitrógeno orgánico disuelto; FT: fósforo total; Fdis: fósforo disuelto; PST: peso seco total; PSO: turbidez orgánica; PSI: turbidez inorgánica.

Figure 2. Limnological variables for both study stages. * Significant differences for the same variable between the study stages are shown (The Mann-Whitney U test, $\left.{ }^{*} \mathrm{P}<0.05,{ }^{* *} \mathrm{P}<0.005\right)$. Prof: depth; $\mathrm{T}$ agua: water temperature; NOT: total organic nitrogen; NOD: dissolved organic nitrogen; FT: total phosphorus; Fdis: dissolved phosphorus; PST: total seston; PSO: organic turbidity; PSI: inorganic turbidity. 
entre las etapas de estudio (Tabla 1, Figura 2). La profundidad de SM osciló entre 0.72 m y $1.45 \mathrm{~m}$, y se duplicó en la etapa II. La conductividad se mantuvo relativamente constante y elevada a lo largo de la etapa I, e inversa al patrón de profundidad. En la etapa II, los valores disminuyeron prácticamente a la mitad. La amplitud térmica del agua de la laguna fue mayor en la etapa I, registrándose los máximos de temperatura al inicio del estudio $\left(29^{\circ} \mathrm{C}\right.$ en diciembre 2013 y $28{ }^{\circ} \mathrm{C}$ en enero de 2014).

$\mathrm{El} \mathrm{pH}$ de la laguna se mantuvo relativamente constante y elevado a lo largo del estudio, correspondiendo a aguas alcalinas. Las concentraciones de oxígeno disuelto fueron elevadas, con medias mayores a $9 \mathrm{mg} / \mathrm{L}$ (excepto diciembre de 2013 con $4.5 \mathrm{mg} / \mathrm{L}$ ), siendo más estables en la etapa II.

Los patrones temporales de las concentraciones de NOT y NOD fueron similares en ambas etapas, con valores muy altos (medias: 5.29 y $3.76 \mathrm{mg} / \mathrm{L}$, respectivamente). Las concentraciones de FT y Fdis fueron más elevadas al inicio de las etapas, con un máximo de FT en noviembre de $2013(0.9 \mathrm{mg} / \mathrm{L})$. La transparencia fue muy baja en ambas etapas $(<28 \mathrm{~cm})$, y en la segunda, los valores fueron incluso menores, llegando a un mínimo de $6 \mathrm{~cm}$ en noviembre 2014. La contribución de las distintas fracciones del seston fue variando a lo largo del estudio. En la Figura 2e se destaca que en la etapa I, el PSO fue mayor que el PSI, mientras que en la etapa II, el PSI registró valores más variables y mayores que el PSO. En particular, al comienzo de la etapa II, los valores de PSI fueron muy elevados, representando casi la totalidad del PST. La concentración de Chl- $a$ varió entre 21.5 y $419.7 \mu \mathrm{g} / \mathrm{L}$; en la etapa I, los valores por lo general fueron mayores, entre 253 y $420 \mu \mathrm{g} / \mathrm{L}$ (excepto en diciembre de 2013, con $23 \mu \mathrm{g} / \mathrm{L}$ ), mientras que los valores iniciales en la etapa II fueron 152 y $314 \mu \mathrm{g} / \mathrm{L}$ (noviembre de 2014 y enero de 2015, respectivamente); luego disminuyeron hasta $32 \mu \mathrm{g} / \mathrm{L}$. La concentración media de Chl- $a$ fue mayor al límite superior correspondiente al estado eutrófico (19.2 $\mu \mathrm{g} / \mathrm{L})$, lo que indica un estado hipereutrófico (Moss 2010).

El ACP explica el $60 \%$ de la varianza de las variables físicas y químicas entre los dos primeros ejes (Figura 3). El primer eje contribuye a la varianza total en $34.3 \%$ y se correlaciona principalmente con el PSI $(\mathrm{r}=0.91)$, el PST $(\mathrm{r}=0.91)$, la turbidez $(\mathrm{r}=0.86)$ y la concentración de FT ( $\mathrm{r}=0.76)$. El segundo eje explica un $25.7 \%$ de la varianza total y se correlaciona con el PSO ( $\mathrm{r}=-0.92)$, la transparencia $(\mathrm{r}=0.63)$, el oxígeno disuelto $(\mathrm{r}=-0.73)$, el $\mathrm{pH}(\mathrm{r}=-0.65)$ y la profundidad $(\mathrm{r}=0.57)$.

\section{Ensamble de cianobacterias formadoras de floraciones}

Abundancia y biovolumen. La densidad total de cianobacterias se mantuvo elevada (>1.3*10 $10^{4}$ cél. $/ \mathrm{mL}$ ) a lo largo del estudio, siendo

Tabla 1. Valores mínimos, máximos y medios de las variables limnológicas medidas y sus desvíos estándar entre paréntesis para ambas etapas de estudio.

Table 1. Minimun, maximun and mean values of limnological variables measured and their standard deviations in parentheses for both study stages.

\begin{tabular}{lcccccc}
\hline & \multicolumn{3}{c}{ Etapa 1: nov. 2013 - may. 2014 } & \multicolumn{3}{c}{ Etapa 2: nov. 2014 - may. 2015 } \\
& Mín. & Máx. & Media & Mín. & Máx. & Media \\
\hline Profundidad $(\mathrm{m})$ & 0.72 & 0.87 & $0.78(0.07)$ & 1.20 & 1.45 & $1.37(0.10)$ \\
Secchi $(\mathrm{cm})$ & 8.00 & 21.00 & $11.57(4.58)$ & 6.00 & 28.00 & $15.86(8.49)$ \\
T agua $\left({ }^{\circ} \mathrm{C}\right)$ & 15.50 & 29.00 & $23.21(5.01)$ & 22.50 & 27.00 & $24.50(1.50)$ \\
$\mathrm{O}_{2}(\mathrm{mg} / \mathrm{L})$ & 4.50 & 13.50 & $10.76(3.15)$ & 6.00 & 10.80 & $9.33(1.69)$ \\
$\mathrm{pH}$ & 8.84 & 9.48 & $9.15(0.25)$ & 8.62 & 9.18 & $8.84(0.22)$ \\
Conductividad $(\mu \mathrm{s} / \mathrm{cm})$ & 3.08 & 3.37 & $3.23(0.11)$ & 1.48 & 1.86 & $1.67(0.16)$ \\
Turbidez $(\mathrm{NTU})$ & 45.20 & 149.00 & $120.74(35.00)$ & 33.50 & 226.00 & $118.57(83.37)$ \\
PST $(\mathrm{mg} / \mathrm{L})$ & 39.00 & 136.00 & $100.00(33.80)$ & 45.00 & 253.00 & $125.14(80.77)$ \\
PSO $(\mathrm{mg} / \mathrm{L})$ & 19.50 & 73.50 & $59.21(17.87)$ & 19.00 & 56.00 & $31.57(14.60)$ \\
PSI $(\mathrm{mg} / \mathrm{L0}$ & 16.00 & 73.00 & $40.79(21.28)$ & 22.00 & 204.00 & $93.57(67.65)$ \\
FT $(\mathrm{mg} / \mathrm{L})$ & 0.02 & 0.89 & $0.33(0.27)$ & 0.19 & 0.58 & $0.39(0.17)$ \\
Fdis $(\mathrm{mg} / \mathrm{L})$ & $<0.005$ & 0.40 & $0.14(0.13)$ & 0.06 & 0.38 & $0.18(0.10)$ \\
NOT $(\mathrm{mg} / \mathrm{L})$ & 3.25 & 9.76 & $5.30(2.21)$ & 4.01 & 7.94 & $5.29(1.48)$ \\
NOD $(\mathrm{mg} / \mathrm{L})$ & 1.79 & 5.58 & $3.56(1.25)$ & 2.63 & 4.89 & $3.96(0.79)$ \\
Clorofila $a(\mathrm{mg} / \mathrm{L})$ & 22.76 & 419.73 & $295.47(133.85)$ & 21.49 & 313.54 & $93.50(106.59)$ \\
\hline
\end{tabular}




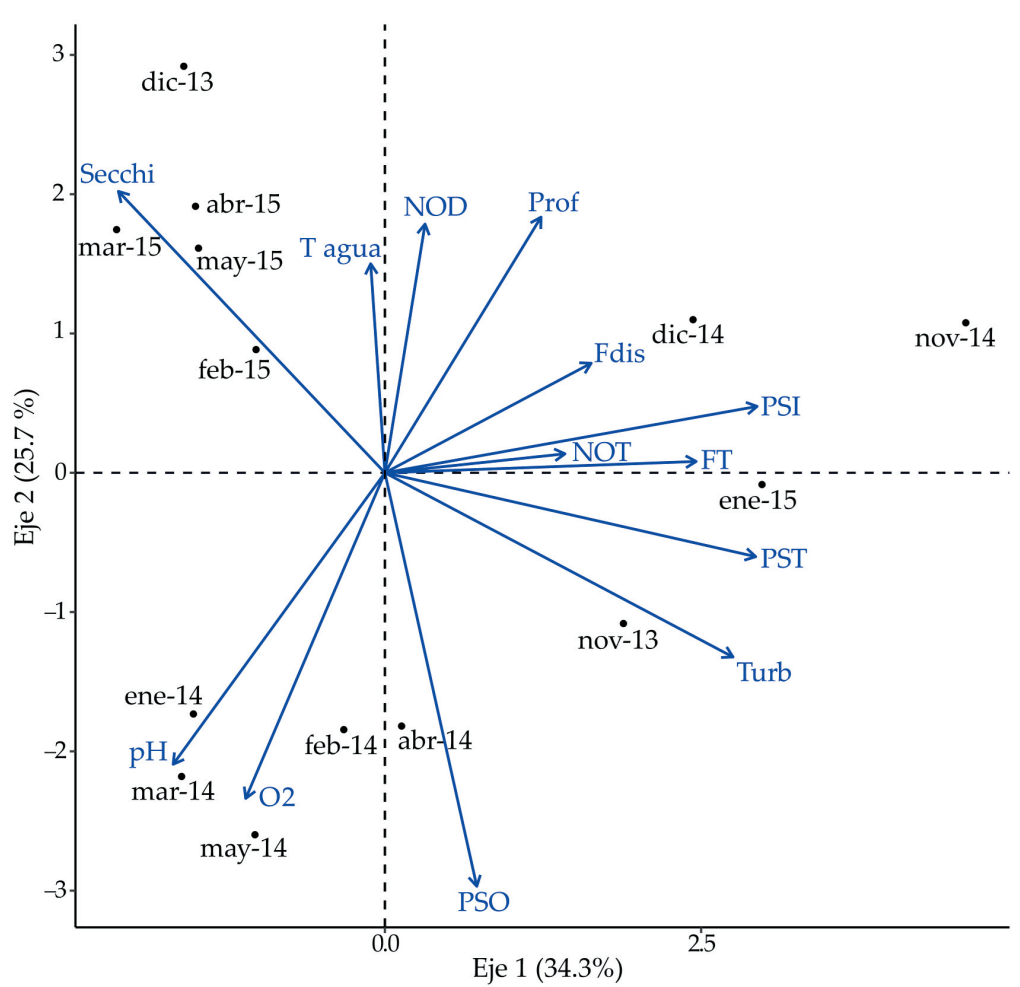

Figura 3. Análisis de componentes principales (ACP) basado en los datos de las variables ambientales para todos los meses muestreados en SM. T agua: temperatura del agua; $\mathrm{O}_{2}$ : oxígeno disuelto; Prof: profundidad; NOT: nitrógeno orgánico total; NOD: nitrógeno orgánico disuelto; FT: fósforo total; Fdis: fósforo disuelto; Turb: turbidez; PST: peso seco total; PSO: turbidez orgánica; PSI: turbidez inorgánica; Secchi: transparencia.

Figure 3. Principal component analysis (PCA) based on the data of environmental variables for all the months sampled in SM. $\mathrm{T}$ agua: water temperature; $\mathrm{O}_{2}$ : dissolved oxygen; Prof: depth; NOT: total organic nitrogen; NOD: dissolved organic nitrogen; FT: total phosphorus; Fdis: dissolved phosphorus; Turb: turbidity; PST: total seston; PSO: organic turbidity; PSI: inorganic turbidity; Secchi: transparency. mayor en la etapa I (3511343 cél./mL; $2.75^{*} 10^{12}$ cél.//m²) que en la II (296100 cél./mL; 3.99* $10^{11}$ cél. $\left./ \mathrm{m}^{2}\right)$, y se correlacionó estrechamente con el biovolumen $(r=0.97 ; \mathrm{P}<0.05)$. En la etapa I, la densidad de las cianobacterias fue muy alta, en coincidencia con una menor profundidad de la laguna, mientras que en la etapa II disminuyó ante un aumento de la profundidad. A su vez, las mayores densidades de cianobacterias totales en la etapa I se correspondieron con mayores temperaturas (Figura 4). Sin embargo, no se evidenció una correlación significativa entre profundidad y biovolumen $(\mathrm{r}=-0.50$; $\mathrm{P}>0.05)$ ni entre profundidad y densidad ( $\mathrm{r}=-$ 0.52; $>>0.05$ ).

Se registraron cinco especies planctónicas formadoras de floraciones potencialmente tóxicas: Anabaenopsis cf. circularis, Anabaenopsis cunningtonii, Cuspidothrix issatschenkoi, Raphidiopsis mediterranea (orden Nostocales) y Planktothrix agardhii (orden Oscillatoriales) (Figura 4d). Estas coexistieron algunos meses, mientras que al inicio de la etapa II se encontró únicamente a $R$. mediterranea, que estuvo presente en todos los meses muestreados y fue la especie que presentó mayor densidad y biovolumen. P. agardhii estuvo presente sólo en la etapa I, con mayor abundancia en noviembre de $2013\left(2.4^{*} 10^{5}\right.$ cél. $/ \mathrm{mL}$ ). C. issatschenkoi estuvo presente en ambas etapas; en la primera se distribuyó de forma relativamente homogénea, mientras que en la segunda se presentó hacia el final de la temporada de crecimiento. A. cf. circularis se desarrolló en la etapa I (excepto en diciembre de 2013), mientras que $A$. cunningtonii se encontró sólo durante enero, febrero y marzo del 2014. El patrón temporal del biovolumen de las especies en la etapa I, cuando las cinco especies estuvieron presentes en la laguna, coincidió con un menor PSI (media de $40.79 \mathrm{mg} / \mathrm{L})$ respecto al inicio de la etapa II (máximo de $204 \mathrm{mg} / \mathrm{L}$ ), cuando únicamente $R$. mediterranea estuvo presente. C. issatschenkoi se observó a partir de marzo 2015, una vez que el PSI disminuyó a valores similares a los de la etapa I.

El ADR derivó en un modelo que explica el $94 \%$ de la varianza (Figura 5). Sólo el primer eje es significativo, explica el $78 \%$ de la varianza y se correlaciona significativamente con la profundidad, el Fdis y el FT de la laguna $(\mathrm{P}<0.05)$. R. mediterranea se diferencia de las demás especies por estar fuertemente asociada a condiciones de mayor profundidad de los meses de la etapa II; el resto de las especies se asocian a una menor profundidad, característica de la etapa I. P. agardhii mostró la asociación más estrecha con el FT.

Morfología. Los descriptores morfológicos en términos del ancho y longitud del filamento 
ค1
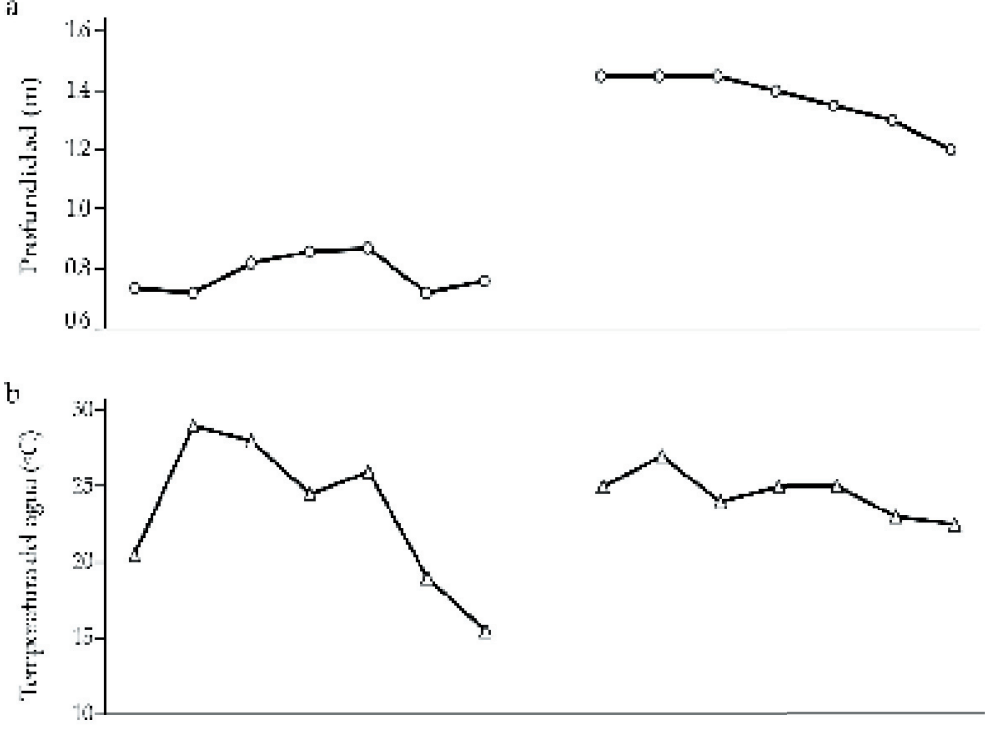

L

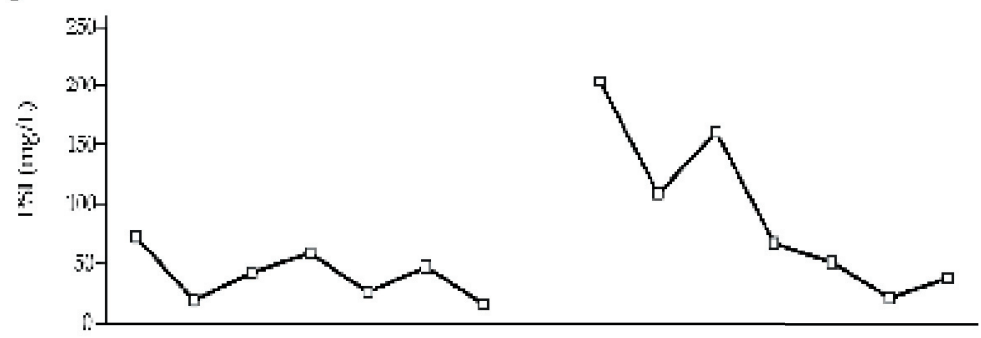

4

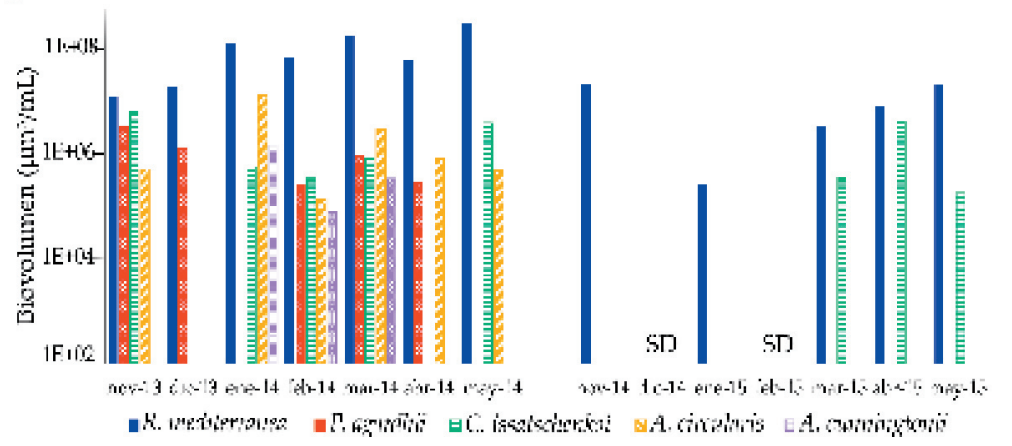

Figura 4. (a) Temperatura del agua, (b) profundidad, (c) peso seco inorgánico (PSI) y (d) biovolumen de las especies características de SM a lo largo del estudio. SD: sin dato.

Figure 4. (a) Water temperature, (b) depth, (c) inorganic dry weight (PSI) and (d) biovolume of characteristic species of SM throughout the study. SD: no data.

Tabla 2. Estadística descriptiva para el ancho y longitud del filamento de las especies de cianobacterias de SM. Frecuencia de células especializadas para las Nostocales (A: acineta; H: heterocito; CV: célula vegetativa). ${ }^{*}$ Ancho mayor que en bibliografía.

Table 2. Descriptive statistics for the width and length of the filament of cyanobacterial species of SM. Frequency of specialized cells for the Nostocal (A: acineta; H: heterocyte; CV: vegetative cell). ${ }^{*}$ Width larger than in bibliography.

\begin{tabular}{lccccccccc}
\hline & \multicolumn{4}{c}{ Ancho del filamento $(\mu \mathrm{m})$} & \multicolumn{2}{c}{ Longitud del filamento $(\mu \mathrm{m})$} & \multicolumn{2}{c}{ Células } \\
& $\mathrm{N}$ & Mín. & Máx. & Media & Mín. & Máx. & Media & A/CV & H/CV \\
\hline R. mediterranea & 239 & 1.38 & 3.44 & $2.27(0.41)$ & 41.43 & 374.88 & $128.35(55.13)$ & 0 & - \\
P. agardhii & 83 & 1.33 & 4.01 & $2.64(0.48)$ & 34.93 & 356.26 & $148.75(77.86)$ & - & - \\
C. issatschenkoi & 115 & 1.76 & 4.05 & $2.79(0.47)$ & 29.36 & 458.64 & $159.00(71.18)$ & 0.010 & 0.036 \\
A. cunningtonii & 32 & 1.96 & 4.98 & $2.95(0.61)$ & 59.69 & 174.66 & $106.99(29.19)$ & 0.006 & 0.161 \\
A. cf. circularis* & 79 & 1.08 & 6.74 & $2.96(1.02)$ & 8.56 & 281.00 & $70.60(42.39)$ & 0.009 & 0.187 \\
\hline
\end{tabular}




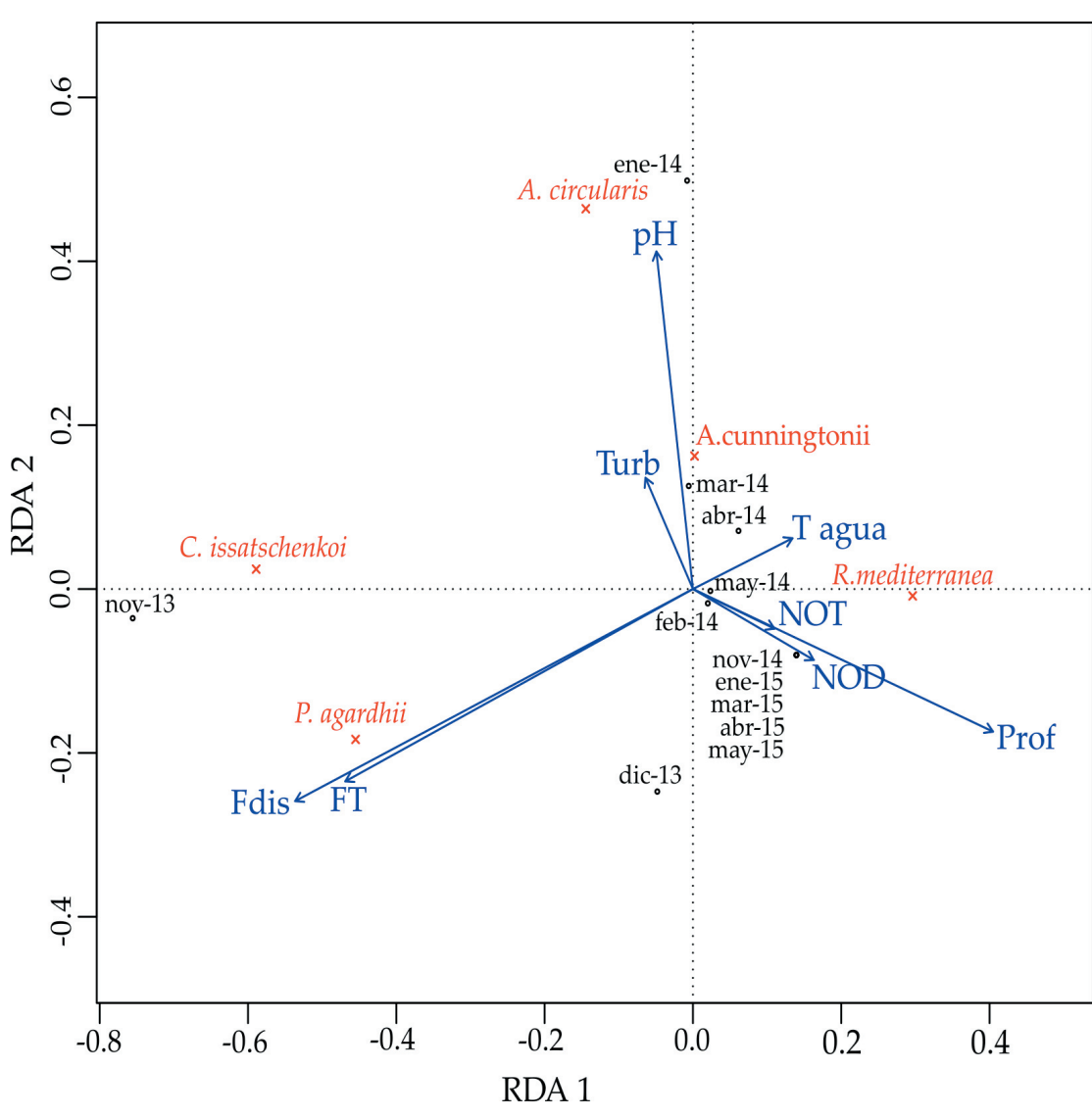

Figura 5. Análisis de redundancia $(\mathrm{ADR})$ entre las variables ambientales y las especies presentes en SM en todos los meses de muestreo. Prof: profundidad; $\mathrm{T}$ agua: temperatura del agua; NOT: nitrógeno orgánico total; NOD: nitrógeno orgánico disuelto; FT: fósforo total; Fdis: fósforo disuelto; Turb: turbidez.

Figure 5. Redundancy analysis (ADR) between environmental variables and species present in $\mathrm{SM}$ in all the months of sampling. Prof: depth, T water: water temperature; NOT: total organic nitrogen; NOD: dissolved organic nitrogen; FT: total phosphorus; Fdis: dissolved phosphorus; Turb: turbidity. de las especies muestran que $R$. mediterranea presentó en promedio los filamentos más finos, con menores valores de máximos absolutos, mientras que los anchos mayores correspondieron a Anabaenopsis, siendo $A$. cf. circularis la que mostró filamentos más gruesos (Tabla 2). Los filamentos más largos en promedio fueron de $C$. issatschenkoi y los más cortos de Anabaenopsis, en particular de A. cf. circularis. Cabe destacar que las especies de cianobacterias dominantes en la laguna tienen filamentos rectos, con excepción de $A$. cf. circularis que se caracteriza por tener filamentos curvos.

Si bien la relación entre el ancho y largo del filamento del total de las especies no mostró patrones definidos, $R$. mediterranea evidenció una relación directa entre ambas variables $(\mathrm{r}=0.30 ; \mathrm{P}<0.05)$. El valor del índice promedio longitud/ancho del filamento difirió entre las cinco especies $(\mathrm{K}-\mathrm{W}=130.53 ; \mathrm{P}<0.05)$ (Figura 6). Los valores del índice de Anabaenopsis fueron generalmente menores a 50 . A. cf. circularis presentó valores significativamente menores al resto de las especies, mientras que $A$. cunningtonii presentó índices menores a $P$. agardhii y R. mediterranea. C. issatschenkoi, P. agardhii y $R$. mediterranea evidenciaron valores mayormente superiores a 50 y similares entre ellos.

En lo que se refiere a las células especializadas características del orden Nostocales, se encontró una baja frecuencia de acinetas (Tabla 2). Mientras que no se encontraron acinetas para $R$. mediterranea, su frecuencia fue menor en las especies de Anabaenopsis que en $C$. issatschenkoi, para la cual sólo se registraron células de dormición en la etapa II (abril de 2015). En particular, A. cf. circularis, A. cunningtonii y $C$. issatschenkoi evidenciaron heterocitos en un rango de 0.006 a 0.258 heterocitos/célula vegetativa. No se encontró una tendencia significativa entre el desarrollo de heterocitos por filamento y la concentración de NOD en la laguna.

Toxinas. El análisis de cianotoxinas reveló distintas variedades de microcistina que sólo se detectaron en la etapa I. Las concentraciones correspondientes a enero, marzo y abril de 2014 son: $0.18 \mu \mathrm{g} / \mathrm{L}$ Mcy-LR, $0.56 \mu \mathrm{g} / \mathrm{L}$ McyLR y $1.615 \mu \mathrm{g} / \mathrm{L}$ Mcy-YR, respectivamente. En ningún caso se registró saxitoxina. 


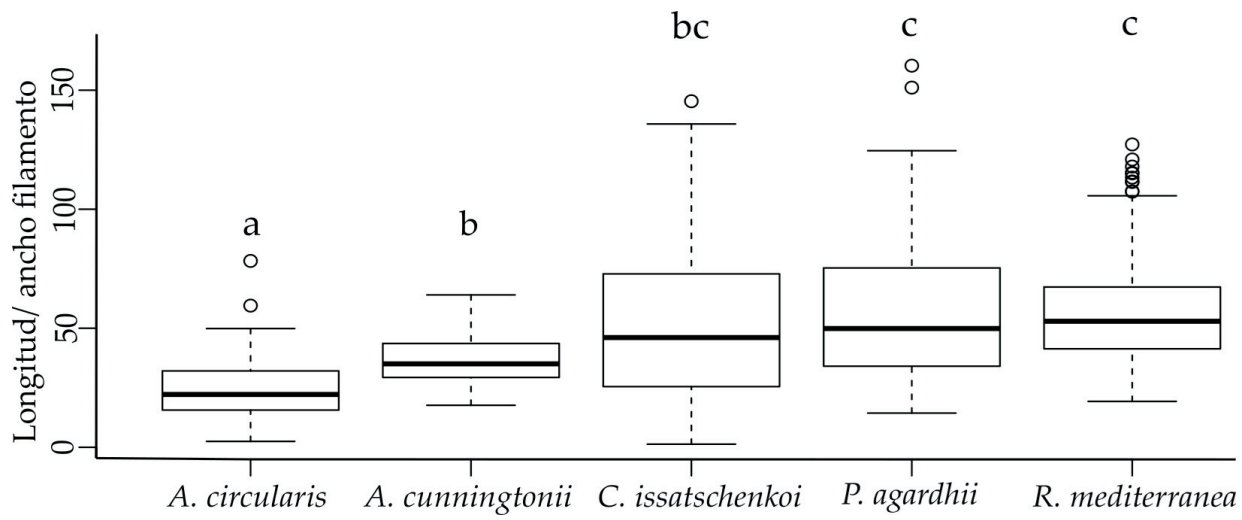

Figura 6. Índice longitud/ancho del filamento para las especies de cianobacterias en estudio. Las letras indican diferencias significativas entre especies $(\mathrm{K}-\mathrm{W}, \mathrm{P}<0.05)$.

Figure 6. Length: filament width index for the cyanobacterial species under study. Letters indicate significant differences between species $(\mathrm{K}-\mathrm{W}, \mathrm{P}<0.05)$.

\section{Discusión}

SM estuvo fuertemente afectada por floraciones de cianobacterias tóxicas durante los períodos cálidos. Las densidades de cianobacterias totales registradas indican no sólo la presencia permanente de floraciones (O'Farrell et al. 2019), sino que excedieron las 100000 cél./mL, superando el nivel guía de alto riesgo para la salud para aguas recreacionales según la OMS (Chorus and Bartram 1999). Las especies características de la laguna son filamentosas y pertenecen a los géneros Planktothrix, Anabaenopsis, Cuspidothrix y Raphidiopsis; $R$. mediterranea fue dominante durante todo el estudio. La abundancia de las especies varió a lo largo del tiempo, principalmente influenciadas por la variabilidad hidrométrica de la laguna, la turbidez y la temperatura del agua.

\section{Abundancia, biovolumen y variables ambientales}

La abundancia de las cianobacterias estuvo estrechamente asociada a cambios del nivel hídrico de esta laguna hipereutrófica, donde la alta disponibilidad de nutrientes no habría influenciado la dinámica temporal de las floraciones. Se descarta que la disminución de densidad de cianobacterias en la segunda etapa se deba a un fenómeno de dilución, ya que al estimar la densidad en función del área se observó una disminución en un orden de magnitud entre la etapa I y II. Tanto el ACP como el ADR diferenciaron ambas etapas en función de la variación de la profundidad de la laguna: el nivel hídrico menor de la etapa I se correspondió con biovolúmenes elevados y una mayor diversidad de especies, mientras que en la etapa II ocurrió lo contrario. La mayor intensidad de las floraciones de cianobacterias de la etapa I ocurrió en condiciones de temperaturas elevadas durante varios días consecutivos y de menor turbidez inorgánica, ocasionando exposición a irradiancias mayores. Contrariamente, en la etapa II se generó una columna de agua más alta, con una marcada turbidez inorgánica al inicio de la temporada, sometiendo a las cianobacterias a bajas irradiancias por mayor tiempo. La disponibilidad de luz en la columna de agua aumenta durante períodos de aguas bajas debido al aumento de la zona eufótica respecto de la profundidad de mezcla ( $>$ Zeu/Zmix); así, se modera la principal restricción para el crecimiento fitoplanctónico, promoviendo una mayor diversidad, tal como fue descripto para la laguna de Chascomús (Iachetti and Llames 2015). La causa del aumento del nivel hídrico en la etapa II estaría relacionada con precipitaciones debidas al evento del Niño registrado como débil para la etapa I, y muy fuerte para la etapa II (inta.gob.ar/ sites/default/files/fenomeno_el_nino_20152016-1.pdf; ggweather.com/enso/oni.html). El efecto de las variaciones hídricas sobre la ecología de las cianobacterias también fue evidenciado en una laguna vegetada de la provincia de Buenos Aires, donde la caída del nivel hídrico promovió el desarrollo de floraciones y un cambio en la composición de especies (O'Farrell et al. 2015). En ambas lagunas se verifica que los filamentos no heterocitados tolerarían las pobres condiciones lumínicas presentes en columnas turbias de mayor profundidad, mientras que las especies fijadoras se verían favorecidas en columnas más cortas y bien iluminadas. En columnas de agua mezcladas y turbias correspondientes a 
lagunas eutróficas y polimícticas (Diovisalvi et al. 2015), las especies de cianobacterias con estrategias dispersivas presentan mayor aptitud ecológica y, por lo tanto, pueden persistir en períodos poco favorables para otras cianobacterias formadoras de floraciones. Tal es el caso de R. mediterranea, cuya presencia exclusiva al inicio de la etapa II, cuando la profundidad y la turbidez inorgánica fueron máximas evidenció la aptitud ecológica de las cianobacterias con morfos rectos y atenuados, atributos que optimizan la captación de la luz (Reynolds 2006). La formación frecuente de floraciones de Raphidiopsis en numerosas lagunas de la región pampeana fue registrada por O'Farrell et al. (2019), sustentado la aptitud ecológica de estas morfologías en sistemas eutróficos someros y turbios. El patrón de abundancia creciente cuando disminuye el nivel hídrico también fue descripto para regiones tropicales de Sudamérica, donde se argumentó que una reducción de la profundidad por las sequías agrava la eutroficación y genera una mayor biomasa y dominancia de cianobacterias (Brasil et al. 2016). La influencia de los cambios marcados de nivel hídrico en la dominancia de este grupo se extiende a otros cuerpos de agua (Jeppesen et al. 2015), como fue ampliamente descripto para los embalses subtropicales de China, donde la caída de nivel dispara la dominancia de cianobacterias (Yang et al. 2016).

La mencionada etapa de aguas bajas en las lagunas de la llanura pampeana estudiadas en el proyecto PAMPA $^{2}$ se relaciona con la ola de calor más extensa registrada para la región (desde el 22 hasta el 30 de diciembre de 2013), con una temperatura máxima absoluta de $39^{\circ} \mathrm{C}$ y una mínima absoluta de $25{ }^{\circ} \mathrm{C}$ (Servicio Meteorológico Nacional; smn.gob.ar/estadisticas). Esta ola coincidió con el inicio de la etapa I (diciembre 2013 y enero 2014) y con los meses de máxima temperatura del agua. Dado que uno de los principales requerimientos para el desarrollo de floraciones de cianobacterias son las altas temperaturas (Paerl and Huisman 2008) y que un rasgo fisiológico relevante de estos organismos es que su tasa de crecimiento se incrementa de forma sostenida con el aumento de la temperatura (Litchman et al. 2010), el evento de la ola de calor explicaría en parte el mayor desarrollo de floraciones en la etapa I. Desde enero de 2014 hasta el final de esta etapa se registraron las cinco especies características de la laguna que fueron variando su abundancia a lo largo de los meses. Su ocurrencia masiva, registrada recién a partir del muestreo del 16 de enero de 2014, podría deberse a que las cianobacterias presentan una de las menores tasas de crecimiento del fitoplancton (Reynolds 2006), resultando en un retraso en el desarrollo de las floraciones más intensas. Por otra parte, la elevada temperatura del agua durante los meses de estudio $\left(>20^{\circ} \mathrm{C}\right)$ contribuiría a la dominancia de $R$. mediterranea, coincidiendo con lo observado en el Lago Doiran (Grecia) donde esta especie prevalece (MoustakaGouni et al. 2010).

En particular, $P$. agardhii se asoció fuertemente a condiciones de mayor concentración de FT en la laguna, lo cual se condice con estudios previos que indican que esta especie es favorecida bajo condiciones turbias con elevadas concentraciones de fósforo (Kokociński et al. 2010). En esa línea, Aguilera et al. (2019) encontraron en otra laguna pampeana que $P$. agardhii tenía una menor actividad fosfatasa que $R$. mediterranea, lo que sugiere una menor tolerancia a la limitación de fósforo.

\section{Morfología}

Las especies filamentosas dominantes en SM funcionan como excelentes 'antenas' de luz, ya que los filamentos largos y delgados se consideran dentro de las formas más eficientes para captar luz (Kirk 1994; Reynolds 1997). La predominancia de especies dispersivas con rasgos morfológicos que maximizan la captación de energía lumínica en SM concuerda con que la relación de profundidad entre la zona eufótica y la de mezcla (Zeu/ Zmix) - considerando a la profundidad de la laguna como Zmix por ser una laguna somera polimíctica - fue menor a 1 en todos los meses muestreados (datos no mostrados) indicando siempre condiciones de baja disponibilidad de luz (Whitton and Potts 2000; Reynolds 2006; Fabre et al. 2010).

Se destaca que Anabaenopsis mostró una menor relación entre el índice longitud/ ancho del filamento y la turbidez respecto de las demás especies. El menor valor del índice correspondiente a $A$. cf. circularis es esperable por su morfología curva y por sus valores de ancho medios mayores y de longitud menores que el resto. $R$. mediterranea registró un índice alto que mantuvo en un amplio rango de turbidez, y fue la única especie que persistió al inicio de la etapa II, cuando la turbidez 
alcanzó los mayores valores debido al aporte elevado de la fracción inorgánica. Sólo $R$. mediterranea evidenció una correlación directa entre el ancho y la longitud del filamento. La relación entre ambas variables morfológicas junto a la presencia de los filamentos más finos en promedio indica que la optimización de la morfología de 'antena' es una estrategia exitosa para mantenerse como la especie dominante a lo largo de ambas etapas de estudio. Los elevados valores de turbidez inorgánica al comienzo de la etapa II podrían haber afectado al desarrollo de las especies que no presentan morfología de 'antena' bien atenuada, lo cual explicaría por qué sólo $R$. mediterranea, y más tardíamente C. issatschenkoi, estuvieron presentes en esta etapa. En este sentido, hay evidencia que sostiene que $R$. mediterranea preferiría condiciones de poca intensidad de luz (Moustaka-Gouni et al. 2010; Iachetti and Llames 2015). Aguilera et al. (2019) concluyeron que la luz es uno de los factores más importante en la sucesión estacional de $R$. mediterranea y $P$. agardhii de la laguna pampeana Los Patos, donde estas especies con morfología de 'antena' persisten y evidencian plasticidad fenotípica ante cambios en las intensidades de luz. Sin embargo, los resultados obtenidos para cada una de las especies no mostraron la relación directa esperada entre turbidez y longitud/ancho del filamento.

Como los valores de turbidez registrados fueron siempre elevados $($ NTU $>21)$, se debería probar si la respuesta morfológica esperada se verifica en un rango más amplio de esta variable, es decir, que una atenuación significativa del filamento ocurra en comparación con aguas levemente más transparentes que las aquí observadas. En la etapa I, cuando $P$. agardhii fue muy abundante y siempre con alto índice longitud/ancho $(>50)$, se registraron los mayores valores de turbidez orgánica. $P$. agardhii y $P$. rubescens son conocidas como las más eficientes para cosechar la luz entre los fitopláncteres (Kurmayer et al. 2016). Scheffer et al. (1997) explicaron que el mecanismo básico de las cianobacterias oscillatoriales para ser competidoras superiores a bajas irradiancias es a través de promover tales condiciones, generando mayor turbidez por unidad de fósforo que las demás algas, lo que es consistente con la asociación registrada entre $P$. agardhii y FT en SM. Al ser comparada con Cylindrospermopsis raciborskii (hoy Raphidiopsis raciborskii), Kokociński et al. (2010) sugieren que la luz es un factor importante en la regulación de la estructura de la comunidad fitoplanctónica y que su modificación puede resultar en cambios desde un ensamble dominado por $P$. agardhii en aguas muy turbias a ensambles más diversos con dominancia de C. raciborskii en aguas más claras.

Otro aspecto importante de los cambios morfológicos de los filamentos se refiere a la diferenciación de las células vegetativas en células especializadas (heterocitos y acinetas). En lagunas más claras de la región pampeana, donde el nitrógeno disuelto se torna limitante debido al elevado consumo fitoplanctónico, se observó que las poblaciones de Nostocales se mantienen abundantes debido a la diferenciación de las células vegetativas en heterocitos (O'Farrell et al. 2015). Para las Nostocales fijadoras de SM no se observó una relación entre el número de heterocitos por célula vegetativa y la concentración de NOD. La falta de relación entre estas variables podría explicarse por el hecho de que SM presentó alta disponibilidad de NOD y las cianobacterias lo consumieron como fuente principal de nitrógeno sin necesidad recurrir a la fijación $\mathrm{N}_{2}$, tal como lo mostró Berman (2001) para el lago Kinneret. De cualquier manera, no se puede descartar que haya ocurrido una diferenciación de heterocitos inducida por baja disponibilidad de NID, como la que caracterizó la primera etapa en $\mathrm{SM}(0.023 \mathrm{mg} / \mathrm{L}$ en promedio para la etapa 1) (Leonardo Lagomarsino, comunicación personal), y en particular debido a que el $\mathrm{NH}_{4}^{+}$suele ser no detectable (L. Lagomarsino, comunicación personal), y es su presencia la que inhibe completamente la fijación de $\mathrm{N}_{2}$ (Kenesi et al. 2009). La baja frecuencia de acinetas encontradas para las especies de género Anabaenopsis y para $C$. issatschenkoi podría deberse a que estas poblaciones no enfrentaron situaciones desfavorables para el crecimiento que desencadenen la diferenciación de estas células de resistencia (Kaplan-Levy et al. 2010).

\section{Toxinas}

La Mcy-LR detectada en la etapa I está considerada como la variante de microcistina más tóxica, seguida por Mcy-YR y Mcy-RR (Gupta et al. 2003); sus concentraciones fueron menores al valor guía ( $1 \mu \mathrm{g} / \mathrm{L}$ Mcy-LR) sugerido por la OMS (Chorus 2012). El valor de Mcy-YR detectado en abril de 2014 fue mayor a dicho valor guía, aunque no se dispone de un valor específico para esta variante. Para los taxones registrados en $\mathrm{SM}$, la literatura indica 
como productoras de microcistina al género Anabaenopsis y a P. agardhii (Carmichael 2001; Bernard et al. 2017). Se sabe que $P$. agardhii produce Mcy-RR (Carmichael 1992; Chorus and Bartram 1999; Dow and Swoboda 2000), toxina que no fue detectada en este estudio. Los pocos registros bibliográficos sobre Mcy-YR se podrían explicar por la falta de equipos y de estándares cromatográficos necesarios para detectar toxinas, ya que habitualmente se utilizan métodos más accesibles e inespecíficos como el ELISA. Hay que considerar que varias especies picoplanctónicas también son potencialmente tóxicas y productoras de microcistina (Jakubowska and Szeląg-Wasielewska 2015), y podrían ser las responsables de alguna de las variantes detectadas en $\mathrm{SM}$, ya que existen reportes de Mcy-LR y Mcy-YR producido por Synechococcus sp. (Sliwinska-Wilczewska et al. 2018). A. cf. circularis fue la única especie potencialmente productora de microcistina presente cuando se registró la toxina y fue la que presentó mayor densidad, pero no hay registros que documenten qué variante de toxina produce. Resultaría poco certero asociar la producción de toxina a una especie en particular, y para ello serían necesarios más estudios que incluyan cultivos o análisis de genotoxicidad.

A pesar de no registrarse valores superiores al nivel guía de la OMS, no se debería subestimar la presencia de cepas tóxicas, ya que SM se utiliza con fines recreativos como la pesca deportiva del pejerrey y el acampe. Por lo tanto, es importante tener en cuenta que en épocas de floraciones los acampantes y los pescadores podrían estar expuestos a los efectos de las toxinas. Además, sería conveniente considerar otros usos potenciales (e.g., deportes acuáticos y baño) y contemplar los riesgos asociados.

\section{Consideraciones finAles}

La laguna Salada de Monasterio está seriamente afectada por floraciones de cianobacterias tóxicas. Los períodos estivales estudiados estuvieron marcados por una gran diferencia de nivel hídrico de la laguna, lo que afectó la turbidez y la concentración de fósforo e influenció el crecimiento, la composición y los atributos morfológicos de los ensambles de cianobacterias. Las condiciones ambientales imperantes y su variación en las dos etapas estudiadas no se asocian con diferenciación de células especializadas para la fijación de $\mathrm{N}_{2}$ o de dormición, lo cual evidencia la ausencia de escenarios de estrés para las especies responsables de las floraciones. Finalmente, la presencia de concentraciones de microcistina total $(>1 \mu \mathrm{g} / \mathrm{L})$ indican alto riesgo para la población humana y los animales silvestres y el ganado, que deben ser considerados por las autoridades locales para gestionar los servicios que provee esta laguna pampeana.

Agradecimientos. En el marco del proyecto PAMPA $^{2}$, agradecemos la financiación del CONICET y del equipo involucrado del IEGEBA y del IIB-INTECH que participaron en los muestreos y en el trabajo de laboratorio. Agradecemos al Laboratorio Litoral SA por el análisis de saxitoxinas y al Laboratorio Central AySA por el análisis de microcistinas. Agradecemos también a las encargadas del club de pesca "Laguna La Salada" por su ayuda y colaboración en el trabajo de campo.

\section{REFERENCIAS}

Aguilera, A., S. Haakonsson, M. V. Martin, G. L. Salerno, and R. O. Echenique. 2017. Bloom-forming cyanobacteria and cyanotoxins in Argentina: A growing health and environmental concern. Limnologica 69:103-114. https:/doi.org/ 10.1016/j.limno.2017.10.006

Aguilera, A., L. Aubriot, R. O. Echenique, J. L. Donadelli, and G. L. Salerno. 2019. Raphidiopsis mediterranea (Nostocales) exhibits a flexible growth under light and nutrient fluctuations in contrast to Planktothrix agardhii (Oscillatoriales). Hydrobiologia 839:145-157. https://doi.org/10.1007/s10750-019-04002-5.

Allende, L., G. Tell, H. Zagarese, A. Torremorell, G. Pérez, J. Bustingorry, R. Escaray, and I. Izaguirre. 2009. Phytoplankton and primary production in clear-vegetated, inorganic-turbid, and algal-turbid shallow lakes from the pampa plain (Argentina). Hydrobiologia 624:45-60. https://doi.org/10.1007/s10750-008-9665-9.

APHA AWWA WEF. 2005. Standard methods for the examination of water and wastewater 21:5-72. Eds American Public Health Association (APHA), American Water Works Association (AWWA), Water Environment Federation (WEF), Washington, DC, USA.

Berg, G. M., P. M. Glibert, N. O. Jørgensen, M. Balode, and I. Purina. 2001. Variability in inorganic and organic nitrogen uptake associated with riverine nutrient input in the Gulf of Riga, Baltic Sea. Estuaries 24(2):204-214. https: //doi.org/10.2307/1352945.

Berman, T. 2001. The role of DON and the effect of N: P ratios on occurrence of cyanobacterial blooms: implications from the outgrowth of Aphanizomenon in Lake Kinneret. Limnology and Oceanography 46:443-447. https://doi.org/ 10.4319/lo.2001.46.2.0443.

Bernard, C., A. Ballot, S. Thomazeau, S. Maloufi, A. Furey, et al. 2016. Appendix 2: Cyanobacteria associated with the production of cyanotoxins. Handbook of Cyanobacterial Monitoring and Cyanotoxin Analysis 501-525. https: //doi.org/10.1002/9781119068761.app2. 
Brasil, J., J. L. Attayde, F. R. Vasconcelos, D. D. Dantas, and V. L. Huszar. 2016. Drought-induced water-level reduction favors cyanobacteria blooms in tropical shallow lakes. Hydrobiologia 770:145-164. https://doi.org/10.1007/s10750015-2578-5.

Carey, C. C., B. W. Ibelings, E. P. Hoffmann, D. D. Hamilton, and J. D. Brookes. 2012. Eco-physiological adaptations that favour freshwater cyanobacteria in a changing climate. Water research 46:1394-1407. https://doi.org/10.1016/ j.watres.2011.12.016.

Carmichael, W. W. 1992. Cyanobacteria secondary metabolites - the cyanotoxins. Journal of applied bacteriology 72: 445-459. https://doi.org/10.1111/j.1365-2672.1992.tb01858.x.

Carmichael, W. W. 2001. Health effects of toxin- producing cyanobacteria: "The CyanoHABs". Human and ecological risk assessment: An International Journal 7:1393-1407. https://doi.org/10.1080/20018091095087.

Chorus, I., and J. Bartram. 1999. Toxic cyanobacteria in water: a guide to their public health consequences, monitoring and management. E and FN Spon, New York. https://doi.org/10.1201/9781482295061.

Chorus, I. 2012. Cyanotoxins: occurrence, causes, consequences. Federal Environment Agency (Umweltbundesamt), Germany.

Diovisalvi, N., V. Y. Bohn, M. C. Piccolo, G. M. E. Perillo, C. Baigún, and H. E. Zagarese. 2015. Shallow lakes from the Central Plains of Argentina: an overview and worldwide comparative analysis of their basic limnological features. Hydrobiologia 752:5-20. https://doi.org/10.1007/s10750-014-1946-x.

Dow, C. S., and U. K. Swoboda. 2000. Cyanotoxins. Pp. 613-632 in B. A. Wihtton and M. Potts. (eds.). The ecology of Cyanobacteria. Kluwer Academic Publishers. Dordrecht. https://doi.org/10.1007/0-306-46855-7_22.

Downing, J. A., Y. T. Prairie, J. J. Cole, C. M. Duarte, L. J. Tranvik, et al. 2006. The global abundance and size distribution of lakes, ponds, and impoundments. Limnology and Oceanography 51:2388-2397. https://doi.org/ 10.4319/lo.2006.51.5.2388.

Fabre, A., C. Carballo, E. Hernández, P. Piriz, L. Bergamino, L. Mello, S. González, G. Pérez, J. León, L. Aubriot, S. Bonilla, and C. Kruk. 2010. El nitrógeno y la relación zona eufótica/zona de mezcla explican la presencia de cianobacterias en pequeños lagos subtropicales, artificiales de Uruguay. Pan-American Journal of Aquatic Sciences 5(1):112-125.

Ferber, L. R., S. N. Levine, A. Lini, and G. P. Livingston. 2004. Do cyanobacteria dominate in eutrophic lakes because they fix nitrogen? Freshwater Biology 49:690-708. https://doi.org/10.1111/j.1365-2427.2004.01218.x.

Fernández Cirelli, A., and P. Miretzky. 2002. Lagos poco profundos de la Pampa Argentina. Relación con aguas subterráneas someras. Pp. 43-52 en A. Fernández Cirelli and G. Chalar Marquesá (eds.). El agua en Iberoamérica. De la limnología a la gestión en Sudamérica. CYTED XVII, CETA-Centro de estudios Transdisciplinarios del Agua, Facultad de Ciencias Veterinarias, Buenos Aires, Argentina.

Figueredo C., G. VonRückert, A. Cupertino, M. Pontes, L. Fernandes, et al. 2014. Lack of nitrogen as a causing agent of Cylindrospermopsis raciborskii intermittent blooms in a small tropical reservoir. FEMS Microbiology Ecology 87: 557-567. https://doi.org/10.1111/1574-6941.12243.

Gupta, N., S. C. Pant, R. Vijayaraghavan, and P. L. Rao. 2003. Comparative toxicity evaluation of cyanobacterial cyclic peptide toxin microcystin variants (LR, RR, YR) in mice. Toxicology 188:285-296. https://doi.org/10.1016/S0300483X(03)00112-4.

Hillebrand, H., C. Dürselen, D. Kirschtel, U. Pollingher, and T. Zohary. 1999. Biovolume calculation for pelagic and benthic microalgae. Journal of phycology 35:403-424. https://doi.org/10.1046/j.1529-8817.1999.3520403.x.

Huisman, J., G. A. Codd, H. W. Paerl, B. W. Ibelings, J. M. H. Verspagen, and P. M. Visser. 2018. Cyanobacterial blooms. Nature Reviews Microbiology 16:471-483. https://doi.org/10.1038/s41579-018-0040-1.

Iachetti, C. M., and M. E. Llames. 2015. Light limitation helps stabilize the phytoplankton assemblage steady-state in a temperate and highly turbid, hypertrophic shallow lake (Laguna Chascomús, Argentina). Hydrobiologia 752:33-46. https://doi.org/10.1007/s10750-014-2045-8.

Izaguirre I., M. L. Sánchez, M. R. Schiaffino, I. O' Farrell, P. Huber, et al. 2015. Which environmental factors trigger the dominance of phytoplankton species across a moisture gradient of shallow lakes? Hydrobiología 752:47-64. https: //doi.org/10.1007/s10750-014-2007-1.

Jakubowska, N., and E. Szelag-Wasielewska. 2015. Toxic picoplanktonic cyanobacteria. Marine drugs 13:1497-1518. https://doi.org/10.3390/md13031497.

Jeppensen, E., S. Brucet, L. Naselli-Flores, E. Papastergiadou, K. Stefanidis, et al. 2015. Ecological impacts of global warming and water abstraction on lakes and reservoirs due to changes in water level and related changes in salinity. Hydrobiologia 750:201-227. https://doi.org/10.1007/s10750-014-2169-x.

Kaplan-Levy, R. N., O. Hadas, M. L. Summers, J. Rücker, and A. Sukenik. 2010. Akinetes: dormant cells of cyanobacteria. Pp. 5-27 in E. Lubzens, J. Cerda and M. Clark (eds.). Dormancy and resistance in harsh environments. Springer, Berlin, Heidelberg. https://doi.org/10.1007/978-3-642-12422-8_2.

Kenesi, G., H. M. Shafik, A. W. Kovács, S. Herodek, and M. Présing. 2009. Effect of nitrogen forms on growth, cell composition and $\mathrm{N}_{2}$ fixation of Cylindrospermopsis raciborskii in phosphorus-limited chemostat cultures. Hydrobiolo gia 623(1):191-202. https://doi.org/10.1007/s10750-008-9657-9.

Kirk, J. T. O. 1994. Light and photosynthesis in aquatic ecosystems. Cambridge University Press. https://doi.org/ $10.2307 / 2403249$.

Kokociński, M., K. Stefaniak, J. Mankiewicz-Boczek, K. Izydorczyk, and J. Soininen. 2010. The ecology of the invasive cyanobacterium Cylindrospermopsis raciborskii (Nostocales, Cyanophyta) in two hypereutrophic lakes dominated by Planktothrix agardhii (Oscillatoriales, Cyanophyta). Eur J Phycol 45:365-374. https://doi.org/10.1080/ 09670262.2010.492916.

Komárek, J., and K. Anagnostidis. 2005. Cyanoprokaryota 2 Teil: Oscillatoriales. Pp. 1-179 in B. Büdel, L. Krienitz, G. Gärtner and M. Schagerl (eds.). Süsswasserflora von Mitteleuropa 19/2. Elsevier, München.

Komárek, J. 2013. Cyanoprokaryota 3 Teil: Heterocystous genera. Pp. 1-1129 in B. Büdel, G. Gärtner, L. Krienitz and M. Schagerl (eds.). Süsswasserflora von Mitteleuropa 19/3. Elsevier, Berlin, Heidelberg.

Kurmayer, R., L. Deng, and E. Entfellner. 2016. Role of toxic and bioactive secondary metabolites in colonization and bloom formation by filamentous cyanobacteria Planktothrix. Harmful algae 54:69-86. https://doi.org/10.1016/ j.hal.2016.01.004. 
Litchman, E., P. de Tezanos Pinto, C. A. Klausmeier, M. K. Thomas, and K. Yoshiyama. 2010. Linking traits to species diversity and community structure in phytoplankton. In Fifty years after the Homage to Santa Rosalia: Old and new paradigms on biodiversity in aquatic ecosystems. Springer, Dordrecht 15-28. https://doi.org/10.1007/s10750010-0341-5.

Lorenzen, C. J. 1967. Determination of chlorophyll and pheo-pigments: spectrophotometric equations. Limnology and oceanography 12:343-346. https://doi.org/10.4319/lo.1967.12.2.0343.

Merel, S., D. Walker, R. Chicana, S. Snyder, E. Baurès, and O. Thomas. 2013. State of knowledge and concerns on cyanobacterial blooms and cyanotoxins. Environment International 59:303-327. https://doi.org/10.106/ j.envint.2013.06.0.13.

Moss, B. 2010. Ecology of freshwaters: a view for the twenty-first century, fourth edition. Wiley-Blackwell. Chichester, UK.

Moustaka-Gouni, M., K. A. Kormas, P. Polykarpou, S. Gkelis, D. C. Bobori, and E. Vardaka. 2010. Polyphasic evaluation of Aphanizomenon issatschenkoi and Raphidiopsis mediterranea in a Mediterranean lake. Journal of Plankton Research 32:927-936. https://doi.org/10.1093/plankt/fbq019.

Neilan, B. A., L. A. Pearson, J. Muenchhoff, M. C. Moffitt, and E. Dittmann. 2013. Environmental conditions that influence toxin biosynthesis in cyanobacteria. Environmental Microbiology 15:1239-1253. https://doi.org/10.1111/ j.1462-2920.2012.02729.x.

Nishiwaki-Matsushima, R., S. Nishiwaki, T. Ohta, S. Yoshizawa, M. Suganuma, et al. 1991. Structure-function relationships of microcystins, liver tumor promoters, in interaction with protein phosphatase. Japanese Journal of Cancer Research 82:993-996. https://doi.org/10.1111/j.1349-7006.1991.tb01933.x.

Nusch, E. A. 1980. Comparison of different methods for chlorophyll and phaeopigment determination. Arch Hydrobiol Beih Ergebn Limnol 14:14-36.

O'Farrell, I., A. Vinocur, and P. de Tezanos Pinto. 2015. Long-term study of bloom-forming cyanobacteria in a highly fluctuating vegetated floodplain lake: a morpho-functional approach. Hydrobiologia 752:91-102. https://doi.org/ 10.1007/s10750-014-1962-x.

O'Farrell, I., C. Motta, M. Forastier, W. Polla, S. Otaño, et al. 2019. Ecological meta-analysis of bloom-forming planktonic Cyanobacteria in Argentina. Harmful Algae 83:1-13. https://doi.org/10.1016/j.hal.2019.01.004.

Oksanen, J., F. G. Blanchet, R. Kindt, P. Legendre, D. Mcglinn, et al. 2019. Package Vegan: Community Ecology Package. $\mathrm{R}$ package version $2-4$.

Paerl, H. W., and J. Huisman. 2008. Blooms like it hot. Science 320:57-58. https://doi.org/10.1126/science.1155398.

Qian, Z. Y., J. Ma, C. L. Sun, Z. G. Li, Q. M. Xian, et al. 2017. Using stable isotope labeling to study the nitrogen metabolism in Anabaena flos-aquae growth and anatoxin biosynthesis. Water Research 127:223-229. https://doi.org/ 10.1016/j.watres.2017.09.060.

Quirós, R., M. B. Boveri, C. A. Petracchi, A. M. Rennella, J. J. Rosso, et al. 2006. Los efectos de la agriculturización del humedal pampeano sobre la eutrofización de sus lagunas. Eutrofizaçãona América do Sul: Causas, conseqüências e tecnologias de gerenciamento e controle 1-16.

R Core team. 2012. R: a language and environment for statistical computing. R Foundation for Statistical Computing, Vienna, Austria.

R Core Team. 2020. R: a language and environment for statistical computing. R Foundation for Statistical Computing, Vienna, Austria.

Reynolds, C. S. 1997. Vegetation processes in the pelagic: a model for ecosystem theory. In O. Kinne (ed.). Excellence in Ecology no 9. Ecology Institute Oldendorf, Germany.

Reynolds, C. S. 2006. The ecology of phytoplankton (Ecology, Biodiversity and Conservation). Cambridge, UK: Cambridge University Press. https://doi.org/10.1017/CBO9780511542145.

Scheffer, M., S. Rinaldi, A. Gragnani, L. R. Mur, and E. H. van Nes. 1997. On the dominance of filamentous cyanobacteria in shallow, turbid lakes. Ecology 78:272-282. https://doi.org/10.1890/0012-9658(1997)078[0272:OTDOFC]2.0.CO;2.

Schindler, D. W. 1977. Evolution of phosphorus limitation in lakes. Science 195(4275):260-262. https://doi.org/10.1126/ science.195.4275.260.

Śliwińska-Wilczewska, S., J. Maculewicz, A. Barreiro Felpeto, and A. Latała. 2018. Allelopathic and bloom-forming picocyanobacteria in a changing world. Toxins 10:48. https://doi.org/10.3390/toxins10010048.

Unrein, F., I. O'Farrell, I. Izaguirre, R. Sinistro, M. dos Santos Afonso, and G. Tell. 2010. Phytoplankton response to $\mathrm{pH}$ rise in a N-limited floodplain lake: relevance of N 2-fixing heterocystous cyanobacteria. Aquatic Sciences 72(2): 179-190. https://doi.org /10.1007/s00027-009-0115-1.

Utermöhl, H. 1958. Zur Vervollkommnung der quantitativen Phytoplankton-Methodik. (For the perfection of quantitative phytoplankton methodology). Mitteilungen. Communications. Internationale Vereinigungfür Theoretische und Angewandte Limnologie 9:1-38. https://doi.org/10.1080/05384680.1958.11904091.

Vega, B. O. Arredondo, B. Cordero Esquivel, and D. Voltolina. 2017. Determinación de peso seco y contenido orgánico e inorgánico. Métodos y herramientas analíticas en la evaluación de la biomasa microalgal. México: Conacyt.

Vrede, T., A. Ballantyne, C. Mille-Lindblom, G. Algesten, C. Gudasz, et al. 2009. Effects of N:P loading ratios on phytoplankton community composition, primary production and $\mathrm{N}$ fixation in a eutrophic lake. Freshwater Biology 54(2):331-344. https://doi.org/10.1111/j.1365-2427.2008.02118.x.

Wood, S., M. Prentice, K. Smith, and D. Hamilton. 2010. Low dissolved inorganic nitrogen and increased heterocyte frequency: precursors to Anabaena planctonica blooms in a temperate, eutrophic reservoir, Journal of Plankton Research 32:1315-1325. https://doi.org/10.1093/plankt/fbq048.

Yang, J., H. Lv, L. Liu, X. Yu, and H. Chen. 2016. Decline in water level boosts cyanobacteria dominance in subtropical reservoirs. Science of the Total Environment 557:445-452.https://doi.org/10.1016/j.scitotenv.2016.03.094.

Zhao, C. S., N. F. Shao, S. T. Yang, H. Ren, Y. R. Ge, et al. 2019. Predicting cyanobacteria bloom occurrence in lakes and reservoirs before blooms occur. Science of the total environment 670:837-848. https://doi.org/10.1016/ j.scitotenv.2019.03.161. 